\title{
On the evolution of power indices in collective bargaining ${ }^{\alpha}$
}

\author{
Siegfried B erninghaus ${ }^{y}$ and Werner G Äth ${ }^{z}$
}

\begin{abstract}
A bstract
Starting point of our (indirect) evolutionary analysis is the sequential bargaining model of Manning (1987) who distinguishes between trade union's power in initial wage and in later employment negotiations. By linking two such collective bargaining situations we can say which of the two (two-dimensional) power constellations is better and thereby derive the power structure endogenously. By distinguishing various measures of (evolutionary or reproductive) success we can identify the forces shaping the relative power indices of trade unions.
\end{abstract}

\footnotetext{
${ }^{x}$ T he authors gratefully acknowledge helpful comments by R onald Bachmann.

YUniversity of Karlsruhe, Institute of Statistics and Mathematical E conomics, Zirkel 2, D - 76128 K arlsruhe, Germany

${ }^{\text {zH }}$ umboldt-U niversity of B erlin, Department of E conomics, Institute for Economic Theory III, Spandauer Str. 1, D - 10178 Berlin, Germany
} 


\section{Introduction}

The literature of collective (but also individual) wage bargaining has been inspired by the cooperative solution of Nash $(1950,1953)$. The so-called Nash-bargaining solution does not require transferable utility (like the so-called TU-games) and can be justi ${ }^{-}$ed both axiomatically and by a non-cooperative representation (the so-called (Nash-)demand game) together with an ad hoc but nevertheless very in ${ }^{\circ}$ uential idea of equilibrium selection (see Harsanyi and Selten, 1988, and G ̈̈th and Kalkofen, 1989). Of all e \pm cient agreements the Nash-bargaining solution picks the one for which the product of agreements dividends (what the parties get in addition to their con ${ }^{\circ}$ ict payo ${ }^{\circledR}$ ) is maximal.

One crucial aspect of the Nash-bargaining solution is its symmetry axiom. Since in most bargaining situations one observes strategic (dis)advantages of one party, this has seriously restricted its predictive success (early experimental tests of the Nashbargaining solution are K alisch, Milnor, Nash, and Nering, 1954, Nydegger and Owen, 1975, and Roth and Malouf, 1979). One therefore (see, for instance, Roth, 1979) has generalized the concept by maximizing the product of weighted agreement dividends. The non-negative exponents (the weights) add up to one and measure the power of the respective bargaining parties. ${ }^{1}$

A further generalization is due to Manning (1987). His basic idea is that relative bargaining power (as measured by the exponents of agreement dividends) may depend on the issue when (collective) bargaining has to specify at least two di ßerent issues, e.g. the (wage) tari ${ }^{\circledR}$ and the employment level. His sequential bargaining model assumes that parties (the trade union and its counterpart) ${ }^{-}$rst determine the wage level and then the employment level where bargaining power of the two parties on the ${ }^{-}$rst and second stage may be di ßerent. Actually extreme asymmetries like these are typically assumed in (micro) economics. So sellers, e.g. monopolists, usually have dictatorial power concerning sales prices whereas customers can dictate how much they order.

A consequence of Manning 1987's generalization is that each pair of power indices in the unit sqare represents a di ßerent bargaining model. This large variety can be viewed as a chance when trying to achieve a better ${ }^{-} t$ in econometric applications but also as a dilemma since hardly anything can be concluded for the result without knowing the two power indices. Our approach tries to resolve this dilemma by not imposing exogenously power indices but by deriving them endogenously. More speci ${ }^{-}$cally, we will derive just one evolutionarily stable constellation of power indices in the unit square where the result may, of course, depend on the speci cation of the evolutionary model.

Methodologically our approach is one of indirect evolution. In indirect evolution one does not model directly the evolution of behavior but of its underlying (institutional) determinants like, for instance, preferences (see G Äth and K liemt, 1998, for a conceptual

\footnotetext{
${ }^{1}$ T here are various axiomatic and procedural, i. e. non-cooperative justi ${ }^{-}$cations of $\mathrm{N}$ ash's bargaining solution which help to understand more thoroughly ist vasic aspects. Here we do not want to discuss this since our main approach is to analyze the evolution of bargaining power in wage and employment bargaining.
} 
discussion). For the case at hand collective bargaining is determined by the two power indices, as suggested by M anning (1987). The power constellation may, however, change over time in view of past success. One may, for instance, switch to other constellations yielding a larger surplus. This, of course, implies a model of evolutionary selection which we provide by linking two parallel collective bargaining situations. By distinguishing several evolutionary models we can point out what determines each of the two power indices in the model of Manning (1987).

The following section describes the fundamental set up, the special model of $M$ anning (1987, section IV). We then link two parallel bargaining situations what allows us to compare the (evolutionary or reproductive) success of one power constellation with another. Section 4 studies the evolution of two-dimensional bargaining power for the (a \pm ne) speci cation of this linkage whereas section 5 is devoted to the homogeneous but non-linear case. In our Conclusions we summarize and discuss our results.

\section{The basic model}

Although this is more questionable when collective wage bargaining is more (above the - $r$ level) centralized, a party's bargaining power may depend on the issue, i.e. on the aspect which is to be negotiated like the size of the labour force or the wage tari ${ }^{\circledR} S$. In collective bargaining at the ${ }^{-} \mathrm{rm}$ level it may depend on the alternative jobs of employees whether the union is relatively strong or weak when negotiating how large the labour force should be. Similarly, the excess of status quo \{ wages over social bene ${ }^{-}$ts and the (disutility of) work stress can be decisive for union's strength when bargaining about wage tari ßS. In this sense of independent bargaining power for wages and employment $M$ anning (1987) has generalized collective wage bargaining where he assumes that items (wages, respectively employment levels) are negotiated sequentially (see M anning, 1987, section I, for some earlier models which qualify as special cases of his general model).

We only introduce the special model ${ }^{2}$ of Manning (1987, section IV). The ${ }^{-} \mathrm{rm}$ and the trade union negotiate both,

2 the wage level $w$ and

2 the size $L$ of the labour force.

Payo ${ }^{\circ}$ depend on the these two variables as follows:

$$
\text { I }(w ; L)=f(L) ; w \Phi L
$$

is the ${ }^{-} \mathrm{rm}^{\prime} \mathrm{s}$ pro't resulting from total production $f(L)$, depending positively on $L$, minus labour cost $w \mathbb{L}$. Let $b(, 0)$ denote employees' aspiration level below which they would refuse to work, e.g. by organizing so-called wild strikes and thereby threatening

\footnotetext{
${ }^{2}$ The general version allows for more general payo ${ }^{\circledR}$ and production functions.
} 
the (relevance of the) trade union. Manning (1987, p. 128) refers to $b$ as $\backslash$ the level of utility available to union members elsewhere". The trade union is both interested in a high excess wage $(w ; \quad b)$ and in a large labour force $L$. Its simple payo ${ }^{\circledR}$ function is

$$
U(w ; L)=(w ; b) \& L:
$$

A n important aspect of our study is to show

2 how the level $b$ can be endogenously determined by considering parallel collective negotiations, e.g. for other ${ }^{-}$rms, branches, regions, and

2 how this in ${ }^{\circ}$ uences which bargaining strength one has to expect in the long run.

Parties (the ${ }^{-} \mathrm{rm}$ management and the trade union)

2 - rst select $w$ by maximizing

$$
U(w ; L)^{p} C_{1}^{\prime}(w ; L)^{1_{i} p} \text { or } \operatorname{plnU}(w ; L)+(1 ; p) \ln (w ; L)
$$

with $\mathrm{p} 2[0 ; 1]$ measuring the union's bargaining power in wage bargaining and

2 then determine $L$ via maximizing

$$
U(w ; L)^{q} \Phi_{1}(w ; L)^{1}{ }^{1} q \text { or } \quad \ln U(w ; L)+(1 ; q) \ln (w ; L)
$$

for given w where now q $2[0 ; 1]$ is the union's bargaining strength when negotiating the employment level $L$ at a given wage $w$.

For the speci ${ }^{-}$c production function

$$
f(L)=L^{-} \text {with } 0<^{-}<1
$$

the solution can be easily derived as

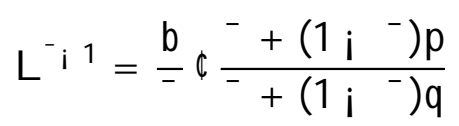

and

$$
w=\frac{b}{=}\left({ }^{-}+\left(1 i^{-}\right) p\right):
$$

By variation of $p$ and $q$ one can represent special cases in the collective bargaining literature, e.g.

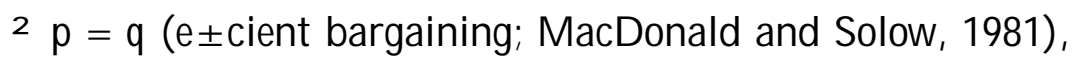

${ }^{2} \mathrm{p}=1=1 ; \mathrm{q}$ (union monopoly; Dunlop, 1944, and Oswald, 1982),

2 p $2(0 ; 1), q=0$ ( right to manage-models"; Nickell, 1982). 


\section{Parallel collective negotiations}

Collective negotiations do not occur in isolation but parallel with similar negotiations in other ${ }^{-} \mathrm{rms}$, branches, and/ or regions with might in ${ }^{\circ}$ uence each other mutually. Especially \the level of utility available to union members elsewhere" (Manning, 1987, p. 128) will usually and strongly depend on what happens in other collective negotiations (for earlier attempts to capture such dependencies see Gäth, 1978). Let us refer by $\mathrm{i}=1 ; 2$ as the two ${ }^{3}$ parallel collective negotiations whose payo ${ }^{\circledR S}$ are ${ }_{i}\left(w_{i} ; L_{i}\right)$ and $U_{i}\left(W_{i} ; L_{i}\right)$, respectively, and whose bargaining strengths are given by

$$
p_{i} ; q_{i} 2[0 ; 1] \text { for } i=1 ; 2 \text { : }
$$

The outside option levels $b_{1}$ are assumed to be interrelated in the form ${ }^{4}$ of

$$
b_{1}=c+d w_{j} \text { for } i ; j=1 ; 2 \text { and } i \epsilon j
$$

with $c>0$ and $0<d<p_{\overline{2^{-2}+3 i 4^{-}}}$. Inserting (9) into the equation (7) for $w_{i}$ yields

$$
w_{i}={ }^{\circ} i+\sharp w_{j} \text { for } i ; j=1 ; 2 \text { and } i \in j
$$

where

$$
o_{i}=\frac{c}{=}\left[-+\left(1 i^{-}\right) p_{i}\right] \text { and } \pm=\frac{d}{=}\left[-+\left(1 i^{-}\right) p_{i}\right] \text { : }
$$

The solution of the two equations (10) in $w_{1}$ and $w_{2}$ is given by

$$
w_{i}=\frac{{ }^{0}++_{+}^{\circ} j}{1 i \text { t+ }} \text { for } i ; j=1 ; 2 \text { and } i \in j:
$$

Now ${ }^{\circ}$ and $\ddagger$ depend on $p_{i}$ and ${ }^{\circ}$ and $\ddagger$ on $p_{j}$ so that $w_{i}$ depends on both, $p_{i}$ and $p_{j}$, what justi ${ }^{-}$es our shorthand

$$
w_{i}=w_{i}\left(p_{i} ; p_{j}\right) \text { for } i ; j=1 ; 2 \text { and } i \epsilon j
$$

for the two equations (12). Notice that due to $0<{ }^{-}<1, p_{1} ; p_{2} 2[0 ; 1], c>0$, and the restriction for $d$ one has

$$
\begin{aligned}
\pm_{1} \pm_{2} & =\frac{d^{2}}{-2}\left[{ }^{-2}+{ }^{-}\left(1 i^{-}\right)\left(p_{1}+p_{2}\right)+\left(1 i^{-}\right)^{2} p_{1} p_{2}\right] \\
\cdot & \frac{d^{2}}{-2}\left[{ }^{-2}+2^{-}\left(1 i^{-}\right)+\left(1 i^{-}\right)^{2}\right]=\frac{d^{2}}{-2}<1 ;
\end{aligned}
$$

\footnotetext{
${ }^{3}$ Since we want to apply evolutionary ideas when endogenizing the outside option level $b$, the number $2 \mathrm{re}^{\circ}$ ects the usual number of interacting individuals in evolutionary biology or game theory. It is here assumed for simpli ${ }^{-}$cation and no restriction of our general approach.

${ }^{4} B y$ using the same parameters $c$, $d$, and ${ }^{\circledR}$ we preserve the usual symmetry assumption in evolutionary biology and game theory. Allowing for i-speci ${ }^{-}$c parameters would mean to decide between one or two population-interpretation, respectively evolutionary analysis. One could try to justify the speci cation of job search in case of $\operatorname{con}^{\circ}$ ict in bargaining. A simpler interpretation would view $\mathrm{c}$ as determined by unemployment bene ${ }^{-}$ts and $d$ by how close the work skills, required in both ${ }^{-} r m s$ are.
} 


$$
{ }_{i} ; \sharp>0 \text { for } i=1 ; 2
$$

what implies

$$
w_{i}\left(p_{i} ; p_{j}\right)>0 \text { for } i ; j=1 ; 2 \text { and } i \in j:
$$

The solution wages are always well-de- ned. Inserting them into (9) determines the two outside option levels $b_{1}$ and $b_{2}$ which in turn allow to compute the employment levels $L_{1}$ and $L_{2}$ with the help of equation (6). Thus we have accomplished our ${ }^{-}$rst task, namely to endogenize the outside option level(s) by introducing interrelated collective labor negotiations. The second challenge to derive the bargaining strength parameters $p_{i}$ and $q_{i}$ instead of assuming them exogenously is what we tackle in the next section.

\section{On the evolution of bargaining power}

Compared to the simple set up of Manning's speci ${ }^{-} \mathrm{c}$ model (Manning, 1987, section IV) we so far have only endognized the outside option or minimum aspiration levels $b_{1}$ and $b_{2}$ by linking them to the agreed upon wage in the parallel labor negotiations. This establishes the only structural relationship between the two ongoing labor negotiations ${ }^{5}$.

We do not only want to endogenize these minimum wage requirements $b_{1}$ and $b_{2}$ but also the power parameters $p_{1} ; p_{2} ; q_{1} ; q_{2} 2[0 ; 1]$. If these can assume all possible constellations (due to the linked negotiations this is now even more dimensional than in case of the Manning-model), hardly anything speci ${ }^{-}$c, e.g. regarding e \pm ciency, can be claimed. Let us therefore try to somewhat reduce this large variety of possible power structures as represented by the vectors $\left(p_{1} ; q_{1} ; p_{2} ; q_{2}\right) 2[0 ; 1]^{4}$. In doing so we rely on the indirect evolutionary approach which allows to derive the rules of the game instead of imposing them.

An evolutionary game $i=(M ; R(\Phi)$ is de ned by

2 the strategy/mutant set $M$ which here is given by the set

$$
\text { (p; q) } 2 M=[0 ; 1]^{2}=[0 ; 1] £[0 ; 1]
$$

of union's power parameters $p$ and $q$ and by

2 the ${ }^{-}$tness/ success function

$$
\mathrm{R}((\mathrm{p} ; \mathrm{q}) ;(\boldsymbol{p} ; \boldsymbol{\varphi}))
$$

measuring for all $(\boldsymbol{q} ;)$-monomorphic populations how a strategy/mutant $(p ; q)$ would fare in such an environment.

\footnotetext{
${ }^{5}$ If the ${ }^{-}$rms interact on the same product market, one would have to include an additional structural relationship which is neglected here.
} 
What $\mathrm{R}((p ; q) ;(p ; \varphi))$ essentially measures is the tendency of changing the power structure in the sense that for

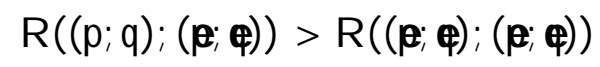

the power parameters $(p ; q)$ will more likely evolve (the processes which can trigger such adaptation will be discussed in the Discussion below). If there exists some vector $\left(p^{a} ; q^{a}\right) 2 M$ such that

$$
\mathrm{R}\left(\left(\mathrm{p}^{\mathrm{\alpha}} ; \mathrm{q}^{\mathrm{\alpha}}\right) ;\left(\mathrm{p}^{\mathrm{\alpha}} ; \mathrm{q}^{\mathrm{\alpha}}\right)\right)>\mathrm{R}\left((\mathrm{p} ; \mathrm{q}) ;\left(\mathrm{p}^{\mathrm{\alpha}} ; \mathrm{q}^{\mathrm{\alpha}}\right)\right)
$$

for all $(p ; q) 2 M$ with $(p ; q) \in\left(p^{\natural} ; q^{\natural}\right)$ we will say that the power structure $\left(p^{\natural} ; q^{\alpha}\right)$ is evolutionarily stable.

It remains to de ${ }^{-}$ne the ${ }^{-}$tness/ success function $\mathrm{R}$ ( $₫$ for the model at hand. Instead of imposing one speci ${ }^{-} \mathrm{c}$ function $\mathrm{R}$ ( $₫$ we consider several reasonable candidates like

(i) $R\left(\left(p_{1} ; q_{1}\right) ;\left(p_{2} ; q_{2}\right)\right)=w_{1}\left(p_{1} ; p_{2}\right)$;

(ii) $R\left(\left(p_{1} ; q_{1}\right) ;\left(p_{2} ; q_{2}\right)\right)=\left(L_{1}\left(p_{1} ; q_{1} ; p_{2} ; q_{2}\right)\right)^{-}$;

(iii) $R\left(\left(p_{1} ; q_{1}\right) ;\left(p_{2} ; q_{2}\right)\right)=w_{1}\left(p_{1} ; p_{2}\right) \Phi L_{1}\left(p_{1} ; q_{1} ; p_{2} ; q_{2}\right)$; or

(iv) $R\left(\left(p_{1} ; q_{1}\right) ;\left(p_{2} ; q_{2}\right)\right)=\frac{w_{1}\left(p_{1} ; p_{2}\right) \mathbb{L}_{1}\left(p_{1} ; q_{1} ; p_{2} ; q_{2}\right)}{\left(L_{1}\left(p_{1} ; q_{1} ; p_{2} ; q_{2}\right)\right)}$ :

In case (i) the basic assumption is that trade unions tend to move to power structures yielding higher wages. This makes sense if the power structure $(p ; q)$ is mainly resulting from trade union's investments in bargaining strength. A similar justi cation can be given for cases (iii) and (iv) where trade union's power structure is induced by the total wage bill, respectively by the wage share. Case (ii), where success is measured by the production amount, allows for a less biased in ${ }^{\circ}$ uence on the power structure. Here the idea is that the power structure is e \pm ciency enhanced so that both parties could pro ${ }^{-} t$ from its adaptation.

Let us start with case (i), i.e. with the agreed upon wage level

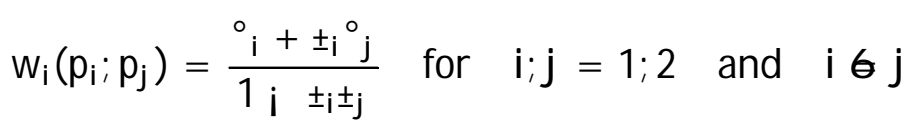

as the (evolutionary or reproductive) success measure. Since $w_{i}(\Phi$ does not depend at all on the power indices $q_{i}$ and $q_{i}$, all power indices

$$
q_{i}^{(x)} 2[0 ; 1] \text { for } i=1 ; 2
$$

are (of course, only weakly) stable. From

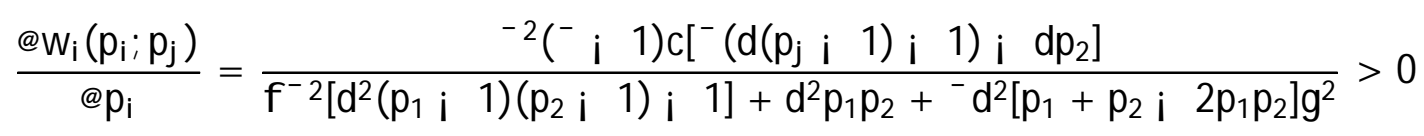


we further obtain

$$
p_{i}^{\alpha}=1 \text { for } i=1 ; 2 \text { : }
$$

For the other speci cations (ii), (iii), and (iv) an analytic result is (in our view, prohibitively) more di \pm cult. We therefore rely on the numerical plots in Figures 1, 2, and 3 for these three speci ${ }^{-}$cations whose clearcut results are as follows: ${ }^{6}$

$$
\begin{aligned}
& 1 / 2 \\
& p_{i}^{\alpha}=0 ; q_{i}^{\alpha}=1 \text { for } i=1 ; 2 \text { and cases (ii) and (iii) } \\
& p_{i}^{\alpha}=1 ; q_{i}^{\alpha}=1 \text { for } i=1 ; 2 \text { and case (iv): }
\end{aligned}
$$

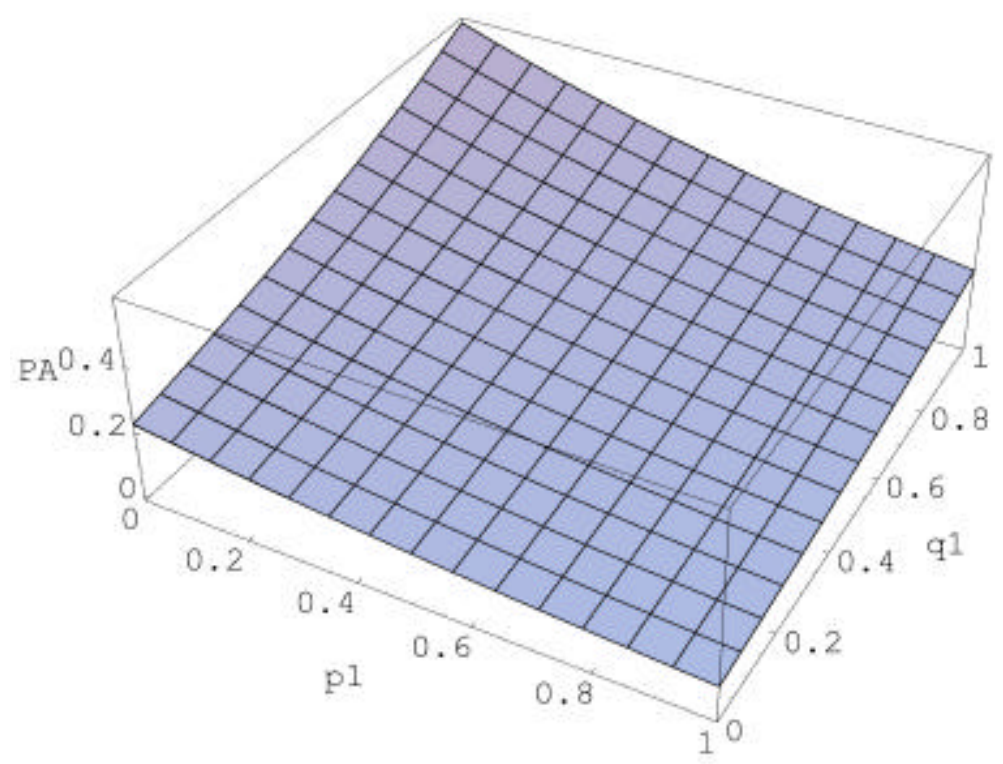

Figure 1: Success measure (ii) with $p_{2}=0: 5 ; c=0: 1 ; d=0: 5 ;$ and $^{-}=0: 9$

\footnotetext{
${ }^{6}$ Our numerical results are robust for di ßering parameter constellations.
} 


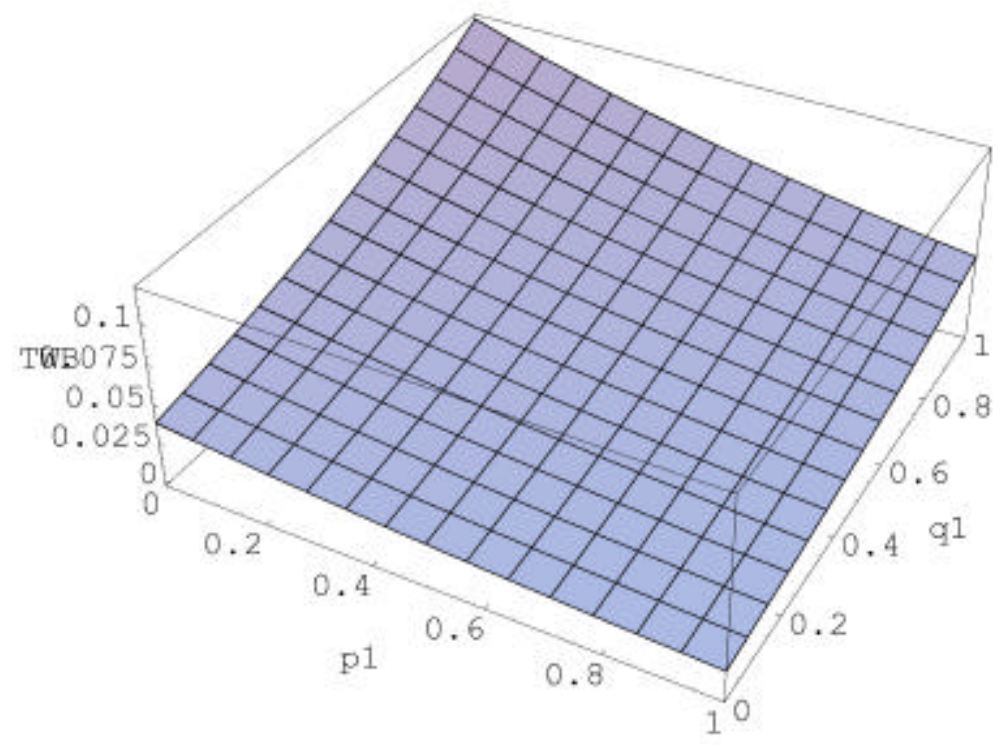

Figure 2: Success measure (iii) with $p_{2}=0: 5 ; c=0: 1 ; d=0: 5 ;$ and $^{-}=0: 9$

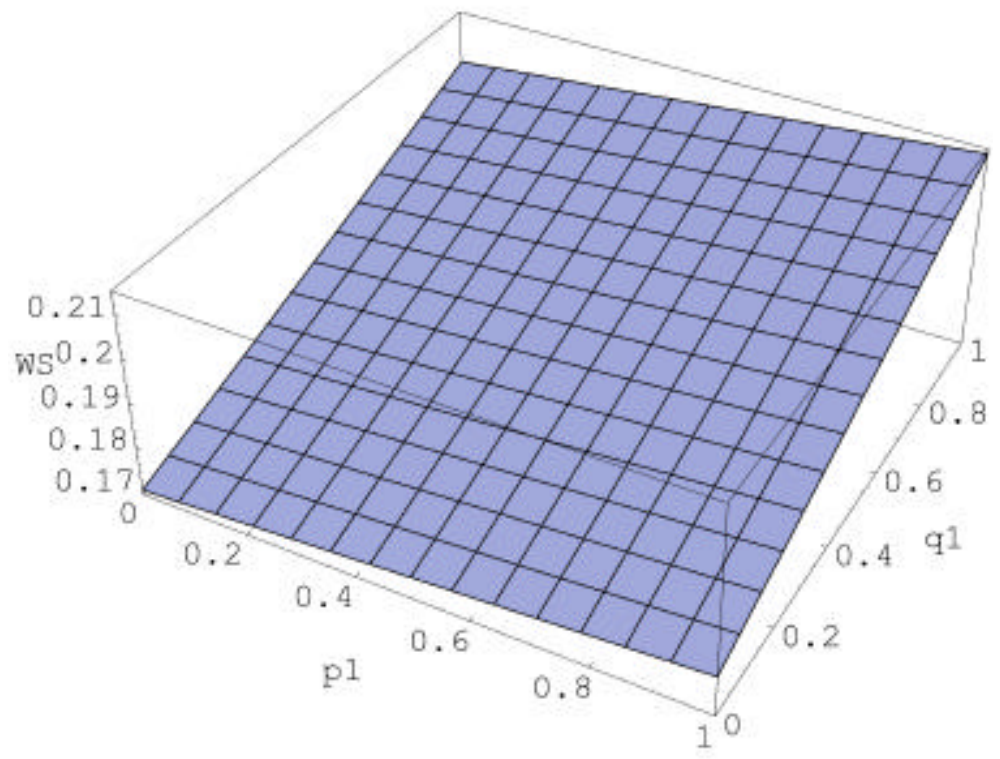

Figure 3: Success measure (iv) with $p_{2}=0: 5 ; c=0: 1 ; d=0: 5 ;$ and ${ }^{-}=0: 9$ 
B efore discussing such results we want to confront them with those where the mathematical form of the mutual dependency of collective labor negotiations is quite di ßerent.

\section{N on-linear interdependencies of outside option lev- els}

If one assumes

$$
b_{1}=w_{j}^{\circledR} \text { with } 0<®<1 \text { for } i ; j=1 ; 2 \text { and } i \in j \text {; }
$$

instead of (9) the wages depend on the power indices $p_{1}$ and $p_{2}$ as follows: ${ }^{7}$

$$
\mathrm{w}_{\mathrm{i}}=\mathrm{k}_{\mathrm{i}} \mathrm{w}_{\mathrm{j}}^{\circledR} \text { for } \mathrm{i} ; \mathrm{j}=1 ; 2 \text { and } \mathrm{i} \in \mathrm{j}
$$

where

$$
\mathrm{k}_{\mathrm{i}}=\frac{-+\left(1 \mathrm{i}^{-}\right) \mathrm{p}_{\mathrm{i}}}{-} \text { for } \mathrm{i}=1 ; 2 \text { : }
$$

According to (26) the outside option levels $b$ become 0 when wages in the other negotiations converge to 0 . This implies rather speci ${ }^{-} \mathrm{c}$ results:

Proposition 1 The evolutionarily stable power $\operatorname{con}^{-}$guration $\left(p_{i}^{\alpha} ; q_{i}^{\alpha}\right)$ for $i=1 ; 2$ must satisfy $p_{i}^{a}=1 ; q_{i}^{a} 2[0 ; 1]$ for case (i);

$$
\begin{array}{ll}
p_{i}^{\alpha}=0 ; q_{i}^{\alpha}=1 & \text { for case (ii), and } \\
p_{i}^{\alpha}=0 ; q_{i}^{\alpha}=1 & \text { for cases (iii) and (iv): }
\end{array}
$$

P roof. We prove the result for case (i); for the other cases the corresponding results are brie ${ }^{\circ}$ summarized in the Appendix. One has

$$
\frac{@ \mathbb{N}_{1}\left(p_{1} ; p_{2}\right)}{@ p_{1}}=i \frac{\left(^{-} i 1\right)\left(\frac{\left(^{-}\left(p_{1} i 1\right) ; p_{1}\right)\left(1+\left(\frac{1}{i} 1\right) p_{2}\right)^{\circledR}}{i^{-}}\right)}{\left(\mathbb{R}^{2} ; 1\right)\left({ }^{-}\left(p_{1} i 1\right) ; p_{1}\right)}:
$$

With the help of

$$
\begin{aligned}
& A_{1}={ }^{-}\left(p_{1} ; 1\right) \text { i } p_{1} ; \\
& A_{2}=1+\left(\frac{1}{-} ; 1\right) p_{2} ; \\
& A_{3}={ }^{-} ; 1 ; \text { and }
\end{aligned}
$$

\footnotetext{
${ }^{7} \mathrm{~A}$ formula comprising both cases, the linear interdependency (9) and the non-linear one in (26), would be $b=c_{i}+d_{i} w_{i}^{\circledR}$ : It would mean that (9) relies on $\AA=1$ and (26) on $c_{i}=0$ and $d_{i}=1$ and that we neglect other possibilities like, for instance, $c_{i}=0$ for $\AA=1$ for which the result is with $w_{1}=w_{2}=0$ trivial. In our view, the a \pm ne linear speci cation (9) and the homogeneous non-linear one in (26) are the more natural assumptions how outside option wages are interrelated.
} 


$$
A_{4}=\mathbb{R}^{2} \mathrm{i} 1
$$

equation (29) can be expressed as

$$
\frac{@ N_{1}\left(p_{1} ; p_{2}\right)}{@ p_{1}}=i \frac{A_{3}\left(i \frac{A_{1} A_{2}^{\circledast}}{-}\right) \frac{1}{1_{i} \Phi^{2}}}{A_{1} A_{4}}:
$$

From $\mathbb{R}^{-}-2(0 ; 1)$ follows

$$
A_{1} ; A_{3} ; A_{4}<0 \text { and } A_{2}>0
$$

so that

$$
\frac{@ \mathbb{N}_{1}\left(p_{1} ; p_{2}\right)}{\mathrm{p}_{1}}>0
$$

what proves that only constellation $\left(p^{\natural} ; q^{\natural}\right)$ with $p^{\alpha}=1$ can be evolutionarily stable. Since $w_{1}$ does not depend on $q_{1}$ or $q_{2}$ there is no evolutionary adaptation of $q$, the trade union's power in employment negotiations. This is di ßerent for the more comprehensive success measures (ii), (iii), or (iv) where one obtains $p_{i}^{a}=0$ and $q_{i}^{a}=1$; for proof see Appendix. $¥$

Thus the non-linear interdependency (26) of outside option values $b_{1}$ will soon or later lead to a so-called I union monopoly" (see Dunlop, 1944, and Oswald, 1982) with $p_{i}^{\alpha}=1$ if the power structure is purely wage guided whereas the opposite result is obtained for the more comprehensive success measures.

\section{Discussion}

Our results are conveniently summarized by Table 1 which lists for $\mathrm{i}=1 ; 2$ the evolutionarily stable power constellations $\left(p_{i}^{a} ; q_{i}^{a}\right)$ for both types ( $\backslash a \pm n e^{\prime \prime}$ or $(9)$, \ non-linear" or (26)) of linking the two parallel bargaining situations as well as for all four measures of (evolutionary or reproductive) success. By $q_{i}^{(x)}$ it is indicated that such levels are only weakly stable. The two linkage types yield the same results when success is measured by the achieved wage level $w_{i}$ (case (i)), by rational product (case (ii)), and by the total wage bill $w_{i} L_{i}$ (case (iii)). For the remaining case the result di ßers: Whereas for the $a \pm n e$ linkage it gets all the power in initial wage bargaining, the non-linear linkage makes it powerless in wage bargaining. Both linkages assign all the power in later employment bargaining to trade unions.

Table 1 illustrates that the stable power constellation can depend on both, the success measure and on the type of linkage. This may be seen as bad or good news:

2 The bad news would be that we wanted to narrow down the wide spectrum of power constellations $\left(\left(p_{1} ; q_{1}\right) ;\left(p_{2} ; q_{2}\right)\right) 2[0 ; 1]^{4}$ : Although the results are mostly unique, they vary partly with the speci ${ }^{-}$cation of success, respectively the type of linkage. Thus there are still (too?) many possibilities. 


\begin{tabular}{|l|c|c|c|c|}
\hline \multirow{2}{*}{$\begin{array}{l}\text { type of } \\
\text { linkage }\end{array}$} & \multicolumn{4}{|c|}{ success measure } \\
\cline { 2 - 5 } & (i) & (ii) & (iii) & (iv) \\
\hline$a \pm n e$ & $p_{i}^{\alpha}=1, q_{i}^{(\alpha)} 2[0 ; 1]$ & $p_{i}^{\alpha}=0, q_{i}^{\alpha}=1$ & $p_{i}^{\alpha}=0, q_{i}^{\alpha}=1$ & $p_{i}^{\alpha}=1, q_{i}^{\alpha}=1$ \\
\hline non-linear & $p_{i}^{\alpha}=1, q_{i}^{(\alpha)} 2[0 ; 1]$ & $p_{i}^{\alpha}=0, q_{i}^{\alpha}=1$ & $p_{i}^{\alpha}=0, q_{i}^{\alpha}=1$ & $p_{i}^{\alpha}=0, q_{i}^{\alpha}=1$ \\
\hline
\end{tabular}

Table 1: The evolutionarily stable power parameters $p_{i}^{a}$ and $q_{i}^{a}$ for the $a \pm n e$ and the non-linear linkage as well as for all 4 success measures

2 A more opportunistic interpretation of our results would claim that we observe di ßerent power constellations in the real world and that our general approach apparently can account for this fact. Especially it may be simply a fact of life that the linkage of two collective labor negotiations is sometimes $a \pm$ ne and sometimes non-linear. Similarly, the success measure guiding the adaptation of the power constellation may vary: Unions, for instance, may primarily care for wages (most likely the less centralized collective bargaining is) but may also be socially responsible (in case of national trade unions) as suggested by the success measure (ii).

2 Although the stable power constellation can change with the linkage type and the speci ${ }^{-}$cation of success, Table 1 also displays quite some robustness. The result $\left(p_{i}^{\alpha} ; q_{i}^{\alpha}\right)=(0 ; 1)$, for instance, can be justi ${ }^{-}$ed by any combination of success measures (ii) and (iii) with linkage types (and also by success measure (iv) for the non-linear linkage).

If a power constellation $\left(p_{i} ; q_{i}\right)$ is better than $\left(p_{j} ; q_{j}\right)$, where $\backslash$ better" is de ned by one of the 4 di ßerent success measures, why and how can the $\mathrm{j}$-trade union (or both parties if the success measure suggests this) adapt a power constellation nearer to $\left(p_{i} ; q_{i}\right)$ ? That such adaptation takes place rests on two assumptions, namely

2 that power parameters can change over time

2 in ways indicated by superior success.

The ${ }^{-}$rst assumption seems hardly restrictive. The strength of trade unions is in- uenced by many factors like their participation rates (which percentage of the labor force is unionized), the general employment situation etc. which are changing over time. Let us therefore concentrate on the latter assumption above. Here the justi ${ }^{-}$cation will strongly depend on the success measure.

If the wage level is the measure of success the change of union power should result from power speci ${ }^{-} c$ investments by trade unions. If, for instance, $\left(p_{i} ; q_{i}\right)$ yields higher wages than $\left(p_{j} ; q_{j}\right)$ since trade union $i$ has a higher participation rate than union $j$, the latter will (re)direct its activities to increase its own participation rate. Similar 
arguments should apply in case of the total wage bill or of the wage quota as success measure.

For the social output (case (ii)) as the measure of success) the adaptation of the power constellation over time could rely on investments by both parties or result from public opinion changes. In a society where capital assets are widely dispersed even the employer side might not object to power structures inspiring a larger social output. If in another region the social surplus is much higher, public opinion will support all attempts to imitate the example of the other region. This would be especially obvious when public opinion directly in ${ }^{\circ}$ uences the power constellation in the sense that trade unions are only strong when their policy is publicly supported.

\section{R eferences}

[1] Dunlop, J . T . (1944): Wage determination under trade union, New York: MacmilIan.

[2] Gäth, W. (1978): Zur Theorie kollektiver Lohnverhandlungen, Baden-Baden: Nomos-Verlag.

[3] Gäth, W. and B. Kalkofen (1989): Unique solutions for strategic games \{ Equilibrium selection based on resistance avoidance, Lecture Notes in Economics and Mathematical Systems No. 328.

[4] Gäth, W. and H. K liemt (1998): The indirect evolutionary approach: B ridging the gap between rationality and adaptation, Rationality and Society 10 (3), 377-399.

[5] Harsanyi, J . C. and R. Selten (1988): A general theory of equilibrium selection in games, Cambridge, Mass.: M.I.T. Press.

[6] K alish, G., J. W. Milnor, J . F. Nash, and E. D. Nering (1954): Some experimental n-person games, in: Decision Processes, R. M. Thrall, C. H. Coombs and R. L. Davis (eds.), New York: W iley, 301-328.

[7] MacD onald, I. M. and R. M. Solow (1981): Wage bargaining and employment, American Economic Review 71, 896-908.

[8] Manning, A. (1987): An integration of trade union models in a sequential bargaining framework, The Economic J ournal 97, 121-139.

[9] Nash, J . F. (1950): T he bargaining problem, in: E conometrica 18, 361-382.

[10] Nash, J . F . (1953): T wo-person cooperative games, E conometrica 21, 128-140.

[11] Nickell, S. J . (1982): A bargaining model of the Phillips curve, L.S.E. Centre for Labour Economics, Discussion Paper. 
[12] Nydegger, R. V., Owen, G. (1975): Two person bargaining: An experimental test of the Nash axioms, International J ournal of Game Theory 3, 239-249.

[13] Oswald, A. J . (1982): The microeconomic theory of the trade union, Economic J ournal 92, 269-283.

[14] Roth, A. E., Malouf, M. W. K. (1979): Game-theoretic models and the role of information in bargaining, Psychological Review 86, 574-549.

[15] Roth, A. E. (1979): Axiomatic models of bargaining, Springer Lecture Notes, B erlin-Heidelberg-N ew York. 574-549.

\section{A ppendix}

\section{Proof of Proposition 2:}

For the success measure (ii) we get

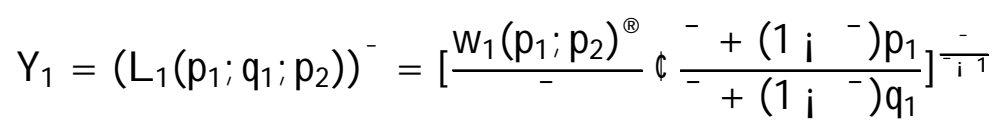

and thus

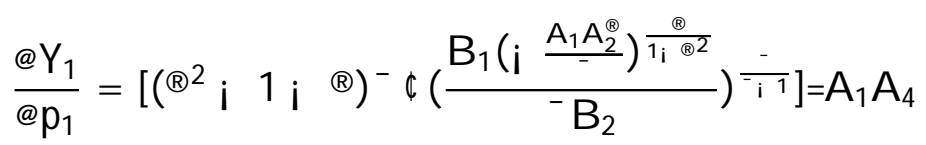

with $B_{1}={ }^{-}+p_{1} i^{-} p_{1}$ and $B_{2}={ }^{-}+q_{1} i^{-} q_{1}$. Since $B_{1} ; B_{2}>0$ and $\mathbb{B}^{2}<1+\circledR$ one has

$$
\frac{\mathrm{Q}_{1}}{\mathrm{q}_{1}}<0
$$

what implies $p_{1}^{\alpha}=0$ :

Similarly,

$$
\frac{\bigotimes_{1}}{\mathbb{Q}_{1}}=\left[i \frac{-\left(B_{1}\left(i \frac{A_{1} A_{2}^{\circledast}}{-}\right)^{\frac{\circledast}{1 i} \otimes^{2}}\right) \frac{\bar{T}}{i 1}}{B_{2}}\right]=B_{3}
$$

with $B_{3}={ }^{-}\left(q_{1} ; \quad 1\right)$ i $q_{1}<0$ implies

$$
\frac{@ r_{1}}{@ q_{1}}>0
$$

and thus $q_{1}^{\mathrm{\alpha}}=1$ : 
For the success measure (iii) or

$$
L S_{1}=w_{1}\left(p_{1} ; p_{2}\right) \notin L_{1}\left(p_{1} ; q_{1} ; p_{2}\right)
$$

one obtains

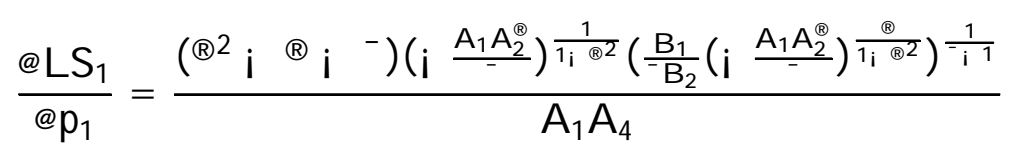

and thus due $\mathbb{B}^{2}<{ }^{-}+^{-}$that

$$
\frac{\mathfrak{Q} \mathrm{S}_{1}}{\mathrm{ap}_{1}}<0
$$

what leads to $p_{1}^{\alpha}=0$.

Similarly,

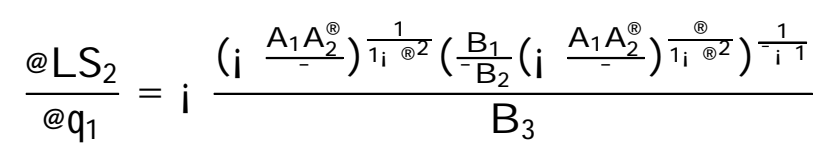

implies $\frac{a_{2} s_{1}}{@_{1}}>0$ and thus $q_{1}^{\natural}=1$ :

F inally, the success measure (iv) or

$$
\mathrm{LQ}_{1}=\mathrm{LS}_{1} \mathrm{~L}_{1}^{-}
$$

yields

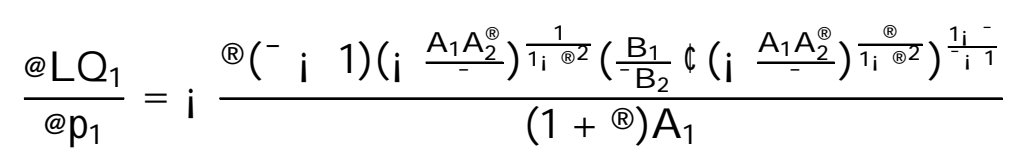

what implies $\frac{Q_{Q} Q_{1}}{Q_{1}}<0$ or $p_{1}^{\alpha}=0$ :

Furthermore

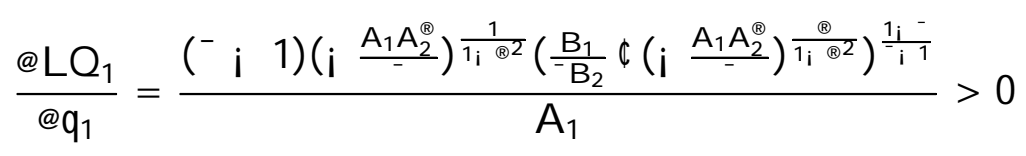

so that $q_{1}^{a}=1: ¥$ 